$300 \mathrm{~nm}$ - and the self-filling micropipettes are designed to be used once and then thrown away. Thus chances of contamination are cut down and speed of operation is increased. A built-in dry well incubator uses a thermistor to maintain a temperature accuracy of better than $0 \cdot 1^{\circ}$. Every mixing operation and cuvette manipulation is done manually, which may put the machine at a disadvantage with its several antomatic competitors now on the market. But its makers claim they would back it against any automatic spectrophotometer in a contest of pure speed.

The machine currently at Houston seems set for fame. No doubt some enthusiast at NASA will put some moon dust straight into a cuvette in the forlorn hope of finding a lunar enzyme, but more serious experiments will be the measurement of biochemical parameters in the collection of animals and plants that is to be exposed to lunar material. The machine has been available in the USA for several months, and is said already to have made a fair impact on the market. The mood of practising doctors in Britain seems to be running somewhat against enzyme assays just now, at any rate for purposes such as the diagnosis of myocardial infarction. But improved assays are under development, and it remains to be seen how the British hospital market will be divided by the current generation of clinical chemistry systems.

\section{QUATERNARY STUDIES}

\section{Motorway into Ice Age}

Excavators preparing the motorway south of Birmingham uncovered a thick layer of ice age peat on Friday last week. Members of the geology department at the University of Birmingham, who salvaged the peat from the maw of the bulldozers, hope that it will provide a mine of information about part of the Pleistocene history of Britain, the period of ice ages which may have ended some 10,000 years ago.

The geologists were prepared for the discovery because of preliminary boreholes dug more than a year ago. The boreholes, part of the standard prospecting for a motorway that will link the M5 and M6, revealed thick layers of peat and silt. Another borehole was sunk by the Institute of Geological Sciences in the thickest part of the layer, and a core removed which probably spans some 50,000 years of deposits.

Dr F. W. Shotton, professor of geology at the University of Birmingham, says that the core has not yet been studied or dated but that it may belong to the Hoxnian interglacial, the last but one of the warm interludes between glacial advances. The Hoxnian interglacial occurred some 200,000 years ago.

This much was known before the motorway intersected the peat layer last week. Spruce cones and seeds of the water chestnut, a species now extinct in Britain, have already been identified. A Hoxnian deposit was discovered north of Birmingham some years ago but the interest of last week's finding is that the deposit apparently covers a complete cycle of climatic change, being sandwiched between layers of clearly glacial debris. Professor Shotton, in whose department the peat will be studied, hopes that the peat will afford a full history of the climatic and biological events that ensued between the retreat of one glacier and the advance of its successor.
TROPICAL MEDICINE

\section{War on Amoebue}

AmokBIAsrs must count as one of the world's major remaining diseases. It is estimated to affect 10 per cent of the population, though its prevalence runs as high as perhaps 80 per cent in Egypt and 56 per cent in Ecuador. A WHO congress on malaria in $1958 \mathrm{em}$ phasized the importance of the disease, and in the intervening years fair progress has been made in its epidemiology and chemotherapeutics. A WHO Expert Committee met in Teheran in 1968 to assess progress, and the report of this meeting has just been issued (Amoebiasis: WHO Technical Report Series, No. 421, Geneva, 1969: 6s).

Six species of amoeba are known to live in the human colon, but Entamoeba histolytica is the only species known to be pathogenic in man, and it is now recognized as the organism behind such conditions as amoebic dysentery, amoebic colitis, amoeboma and amocbic appendicitis. The WHO committee recommends that all these clinical states should be subsumed under the generic title amoebiasis. The presence of $E$. histolytica cysts in human faeces used to be regarded as proof that there had been lesions in the colon mucosa, but this belief has now been abandoned. $E$. histolytica can in fact pass through the human gut inoffensively, and the events-presumably enzymicthat lie behind the onset of pathogenicity are at present not understood.

The encysted amoeba enters new human hosts through their mouths, but it is hard to disentangle the specific epidemiological importance of factors such as contaminated water, food handling, flies, direct faecal contact, overcrowding and the use of night-soil as a fertilizer. New serological techniques are proving useful in the diagnosis of the disease, but perhaps the most hopeful aspect of the situation at present is the appearance of safer and more effective amoebicide drugs.

Drugs that have been familiar in the treatment of amoebiasis for some decades now include quinoline derivatives acting in the bowel lumen; antibiotics, which act in the bowel lumen and wall; emetine, which acts in bowel and liver but is fairly toxic; and chloroquine, which acts in the liver but again can have unpleasant side effects. Two nitroimidazole derivatives have recently been pressed into service, however, and they show powerful activity against amoebae at all their bodily foci. Of the two, metronidazole, already popular in the treatment of trichomoniasis, is the better tolerated.

\section{ANIMAL FOODSTUFFS}

\section{Analysing for Prophylactics}

Methods for the analysis of prophylactic additives to animal feeding stuffs are the latest addition to the Pesticide Residue Analysis Information Service, estab. lished in Britain by the Ministry of Technology in 1965 at the Laboratory of the Government Chemist. The service answers about 250 enquiries a year on methods of analysis for residues of pesticides and their principal degradation and metabolic products.

Prophylactic additives include substances such as amprolium and nitrofurazone as well as the conventional antibiotics. They are added to animal feeds in 